\title{
Enhancing empathy in healthcare: mixed-method evaluation of a pilot project implementing the CARE Approach in primary and community care settings in Scotland
}

\author{
Niamh M Fitzgerald ${ }^{1 *}$, Susie Heywood ${ }^{2}$, Annemieke P Bikker ${ }^{3}$ and Stewart W Mercer ${ }^{4}$
}

\begin{abstract}
Background: The importance of empathic, person-centred care that is responsive to the individual patients' needs is increasingly visible in national and international healthcare policies but there is a need for practical tools to help healthcare practitioners. The CARE Approach is a new 'generic' learning tool that aims to foster the achievement of empathic, person-centred communication in healthcare encounters. This study aimed to evaluate a pilot project which used the CARE Approach in peer facilitated groups in primary and community healthcare settings in Scotland.
\end{abstract}

Methods: The CARE Approach was piloted in 5 sites ( 4 general practice and 1 community rehabilitation team) serving different areas and populations. Evaluation employed a mixed-methods approach, with questionnaires and semi-structured interviews with a purposive sample of participating facilitators and healthcare practitioners.

Results: 131 practitioners took part in the CARE Approach pilot across the five sites. 84 participants (64.1\%) completed a baseline questionnaire and 51 (38.9\%) a post-pilot questionnaire. Semi-structured interviews were conducted with all facilitators and with a purposive sample of 23 participants from the sites. Overall the results indicate that the CARE Approach was perceived as useful and relevant to practice across different disciplines and settings. The flexibility of the CARE Approach materials facilitated its delivery and implementation across the sites. Healthcare professionals' self-perceived empathy at baseline and follow-up suggested a possible impact on daily practice.

Conclusions: The CARE Approach appears to be useful to practitioners in primary and community care and can feasibly be delivered in peer facilitated learning groups. Further work is required to determine the utility of the approach when used in other ways and in other settings and to ascertain the effectiveness of the approach in the longer-term.

Keywords: Empathy, Primary care, Communication skills

\section{Background}

The importance of empathic, person-centred care that is responsive to the individual patients' needs is increasingly visible in national and international healthcare policies [1-4]. As a result, all healthcare staff must be competent in the 'human' as well as 'technical' aspects of care [5,6]. Increasingly, such competence must be demonstrated and thus measurement is important [6,7]. The Consultation

\footnotetext{
* Correspondence: niamh.fitzgerald@stir.ac.uk

'Lecturer in Alcohol Studies, Institute for Social Marketing, UK Centre for Tobacco and Alcohol Studies, University of Stirling, Stirling FK9 4LA, UK Full list of author information is available at the end of the article
}

and Relational Empathy (CARE) Measure was developed as a measure to evaluate empathy in the clinical encounter from the patient's perspective in the United Kingdom [8,9] although it has been validated in several different countries [10-12] and is being widely used internationally. In the UK, the CARE Measure is currently used in the appraisal and revalidation of qualified doctors and for workbased assessment in the postgraduate training of general practitioners (GPs). In Scotland, it has been recommended for use by all healthcare professionals [2] which makes it the first country in the world to put empathy (and its measurement) at the heart of healthcare policy. 
Empathic, patient-centred care is associated with better health outcomes [13-19], higher patient satisfaction [20], and more patient enablement [21]. The measurement and feedback to practitioners of perceived empathy in the clinical encounter is one important step towards improvement, but maintaining or improving empathy in healthcare practitioners is also vital. Several studies have shown that empathy tends to decline over time in healthcare practitioners [22]. Fortunately, there is evidence that training can improve empathy [6,17,23-25].

Although there are numerous 'models' for improving consulting quality, many of these are aimed at specific professionals groups, such as GPs in training, and there appear to be fewer 'generic' training approaches that have been developed to be used across healthcare disciplines and/or in multidisciplinary teams. The CARE Approach is one such a learning tool that aims to foster the achievement of empathic, person-centred communication in healthcare encounters [26,27]. It consists of a written manual with exercises, supported by online film clips covering four interactive components entitled: Connecting, Assessing, Responding and Empowering. The manual can be completed alone or in peerfacilitated small groups. The CARE Approach was derived from the components of the CARE Measure, although it also incorporated learning from the wider international literature and other published models and frameworks [27].

In the present paper we report the evaluation of a project funded by NHS Education for Scotland which piloted the CARE Approach in peer facilitated groups in five primary and community healthcare settings in Scotland. The aim of the evaluation was to explore the feasibility, acceptability and utility of the CARE Approach in supporting learning on communication and human relationships in primary healthcare. Specifically we wished to better understand:

- How did participants and facilitators experience the CARE Approach?

- Did the approach impact on acquisition of knowledge and skills or professional practice?

\section{Methods}

\section{The CARE Approach pilot}

The following five sites (based in two health board areas of Scotland) piloted the CARE Approach between September 2011 and March 2012:

- Site A - Four urban community services including Physiotherapy, Podiatry, Rehabilitation and Enablement teams in Glasgow.

- Site B - General practice in large urban area of Glasgow
- Site C - General Practice in large urban area of Edinburgh

- Site D - General Practice in mid-sized town near Edinburgh

- Site E - General Practice in mid-sized town near Edinburgh

All five sites responded to an advertisement from NHS Education for Scotland and applied to become pilot sites. Practitioners from the five sites acted as peer facilitators, and attended a training day delivered by the developers of the CARE Approach. The facilitator training focused on the content of the CARE Approach and how to deliver it in practice. The CARE Approach manual consisted of six modules entitled:

- What you bring to the encounter

- Connecting

- Assessing

- Responding

- Empowering

- Putting it all together

The modules are supported by online video clips depicting short sections of simulated clinical encounters between healthcare professionals (two GPs, one physiotherapist, one podiatrist) and 'patients' (played by actors).

The same CARE Approach materials were used in each healthcare setting but the practical arrangements for delivery were flexible and open to the discretion and needs of the facilitators and each specific setting. Participation by practitioners in the pilots (though not the evaluation) was managed by each individual pilot site with no involvement from the research team. In total 131 practitioners took part in the CARE Approach pilot across the five sites. In each site the trained facilitators worked through the CARE Approach materials with small, multidisciplinary groups of practitioners. Groups met on between four and six occasions during the pilot and completed at least five of the six modules.

\section{Ethics, sampling and data collection}

The evaluation involved a mixed method approach including quantitative self-report measures, semi-structured questionnaires and qualitative interviews. Under the guidance of the West of Scotland Research Ethics Service [28], ethical approval was not required for the research as it did not involve randomisation or changes to patient care from accepted standards. Data collection took place from October 2011 to March 2012. All 131 pilot participants were fully informed about the evaluation by email, guaranteed the confidentiality of their responses, and invited to complete the questionnaire (a 100\% sample). Of the 131 participants in the pilot projects, 84 
(64.1\%) completed a baseline questionnaire and 51 (38.9\%) a post-pilot questionnaire. Semi-structured interviews were conducted towards the end of the pilot with all facilitators and with a sample of 23 (17.5\%) participants, purposively sampled to include practitioners across all sites and a range of professions and roles. An overview of the content of each questionnaire and of the interview topics is presented in Table 1. A comparison of participants taking part in each stage of the evaluation is presented in Table 2 .

\section{Analysis}

Quantitative data was analysed in Excel and SPSS and results from the two questionnaires were compared. Interviews were audio-recorded and transcribed. Transcripts were analysed thematically using an initial coding framework based on the areas of interest in the interview guide. Segments of interview were coded manually and new codes developed using a general inductive approach as themes emerged from the interviews [29]. The small number of participants involved for the evaluation meant that a comparative analysis of results across different professional groups or sites would not have been robust. The analysis was led by $\mathrm{SH}$ with review by NF and subsequently reviewed by $\mathrm{AB}$ and $\mathrm{SM}$. An independent researcher (JW) and the commissioners of the study (NHS Education for Scotland) also reviewed the analysis.

\section{Results and discussion}

\section{Experiences of the CARE Approach}

Most facilitators and respondents spoke positively about the CARE Approach. It was seen to provide a valuable opportunity for discussions that are often missing from other skills-based training.

"I think we've had conversations that I've never had. I've been qualified 25 years and done tons of postgraduate qualifications and training, and delivered and facilitated quite a lot of training. And I would say it's been quite a revelation to me to hear what people think and how they really feel". Facilitator

"It's not skills-based. It's very much more about your core values, challenging your approaches, challenging historical ways of doing things". Facilitator

The content of the manual was seen by all the facilitators and most staff as useful and relevant. Irrespective of role, experience or seniority, the potential for new learning or reflection as a result of the CARE Approach was apparent from most respondents interviewed. For nonclinical staff, aspects which were identified as being most useful were dealing with difficult situations or aggressive patients, looking at the patient journey through the practice and being non-judgemental about patients. Overall the manual was perceived as well structured, though some respondents felt that the manual was a bit too lengthy.

Most respondents spoke positively about the consultation video clips, how they were used and their usefulness as a discussion prompt.

"They kind of guided us but didn't guide us if you know what I mean. They were sufficiently open but they did stimulate enquiry”. Participant, Site 2

"I think when you can see something you learn better if you can actually watch it and have a chat about it... and hear what everybody else thinks. It was quite funny when we did the videos we all had different views of it, just the views between the teams, between the nurses and the doctors, it really got a discussion going". Participant, Site 3

The short length of the clips and their role in breaking up the exercises was seen as valuable and useful for

Table 1 Overview of data collection instruments

\begin{tabular}{|c|c|c|}
\hline Baseline questionnaire & Post-pilot questionnaire & Post-pilot interview topics \\
\hline Relevant previous training & Self rating based on CARE measure & Reasons for participation \\
\hline Reasons for participating & $\begin{array}{l}\text { Self rating on various statements } \\
\text { related to communication skills }\end{array}$ & Available support (facilitators only) \\
\hline Self rating based on CARE measure & $\begin{array}{l}\text { Self rating on improvements in } \\
\text { knowledge, skills and practice }\end{array}$ & Experience of facilitation (facilitators only) \\
\hline $\begin{array}{l}\text { Self rating on various statements } \\
\text { related to communication skills }\end{array}$ & Most and least useful aspects of approach & $\begin{array}{l}\text { Staff recruitment and engagement } \\
\text { (facilitators only) }\end{array}$ \\
\hline Anticipated achievements & Views on practical arrangements & View on the approach \\
\hline Perceived barriers to implementation & Views on manual, materials and clips & Barriers and facilitators \\
\hline Concerns regarding the approach & Were expectations met? & $\begin{array}{l}\text { Impact on knowledge, skills and } \\
\text { practice (of self and wider team) }\end{array}$ \\
\hline Vision of success & Requirements for implementation & Views on level of success \\
\hline
\end{tabular}


Table 2 Overview of participants

\begin{tabular}{|c|c|c|c|c|}
\hline & $\begin{array}{l}\text { Participants in } \\
\text { pilot }(n=131)\end{array}$ & $\begin{array}{l}\text { Participants completing baseline } \\
\text { questionnaire }(n=84)\end{array}$ & $\begin{array}{l}\text { Participants completing post-pilot } \\
\text { questionnaire }(n=46)\end{array}$ & $\begin{array}{l}\text { Participants completing } \\
\text { semi-structured interviews }\end{array}$ \\
\hline \multirow[t]{14}{*}{ Profession/role } & Physiotherapy & $\mathrm{GPs}=26$ & $\mathrm{GPs}=17$ & $\mathrm{GPs}=6$ \\
\hline & Podiatry & Nurses (including midwives) $=18$ & Nurses (including midwives) $=6$ & Nurses (including midwives) $=5$ \\
\hline & Occupational Therapy & & & \\
\hline & Speech Therapy & AHPs $=26$ & $\mathrm{AHPS}=14$ & $\mathrm{AHPs}=7$ \\
\hline & Dietetics & Other $=14$ & Other $=9$ & Other $=4$ \\
\hline & Nursing & & & \\
\hline & Phlebotomy & & & \\
\hline & Support & & & \\
\hline & GP & & & \\
\hline & Practice Nursing & & & \\
\hline & Counselling & & & \\
\hline & Healthcare Assistant & & & \\
\hline & Midwifery & & & \\
\hline & Administration & & & \\
\hline \multirow[t]{5}{*}{ Site } & $1=48$ & $1=35$ & $1=17$ & $1=8$ \\
\hline & $2=8$ & $2=6$ & $2=4$ & $2=3$ \\
\hline & $3=20$ & $3=9$ & $3=6$ & $3=4$ \\
\hline & $4=23$ & $4=14$ & $4=9$ & $4=4$ \\
\hline & $5=32$ & $5=20$ & $5=10$ & $5=3$ \\
\hline Facilitators & 2 facilitators & 1 facilitator & 1 facilitator & 1 facilitator \\
\hline
\end{tabular}

focus and concentration. A few participants and facilitators reported concerns about the clips including how well they reflected real life and their relevance to the aspect of the CARE Approach they were being used to explain. A few facilitators reported a need to introduce and explain the clips in some cases. This included a discussion on the purpose of the clips, how they had been made, and an explanation that they were not meant to be perfect examples.

\section{The benefit of tailoring the materials to address the} needs of the healthcare setting

A perceived benefit of the CARE Approach was seen to be its flexibility in terms of tailoring the materials to the specific needs and context of the setting. All facilitators reported adapting the CARE Approach materials in some way to fit with the specific needs of the site and their participants, and appreciated the chance to do this.

"I think you have to have a whole variety of methods in any one session, knowing that everyone likes different things and keep it fresh. Keep it changing" Facilitator

"So I did the generic bit, and then went probably a step further and said, what does it mean for our patients? And I think that was the richness of the whole project". Facilitator

Examples of ways in which this was done included different delivery methods to suit different learning styles (e.g. large group, small group or individual work), written materials, practical exercises, working through the module and spending additional time focusing on the needs of the specific practice population.

Respondents were also able to identify the benefits of this more tailored, flexible approach.

"The fact that you could tailor it is good. If you had to work through every single bit of it, and it was very prescriptive, it would have got a tiny wee bit boring. Having someone with that overview, who knows the team and the aspects we're going to concentrate on". Participant, Site 3

The value of the facilitator training day for delivering the CARE Approach

Overall the facilitators were highly satisfied with the one day training provided. It was felt to be useful for background and context and included valuable ideas for facilitation. 
"It was non-threatening, it was very interactive". Facilitator

"It was very, very, easy to plan because they were clearly laid out, they gave ideas how to do it, and quite often the only thing I had to do was put it into a slide format to present it and have it there in the background". Facilitator

Some reported that they had found it a bit too general in nature and there were mixed views on how easy the facilitation materials were to use to deliver the CARE Approach. Some facilitators felt the supporting materials were sufficient, while others felt that more guidance would be helpful.

"It would be helpful to have a little bit more in terms of particular models and techniques that can be used at different modules and at different stages".

\section{Impact of the CARE Approach}

Participants were asked to self-rate themselves depending on how they felt patients perceived them to be in relation to the CARE Measure (on a scale of $1=$ poor to 5 = excellent). Except for item 1 'Making them feel at ease', for all participants the differences identified between the pre and post-pilot scores were statistically significant across the CARE Measure items (Table 3). The greatest increase was for 'Really listening to them', followed by 'Letting them tell their "story" and "Making a plan of action with them'.

Despite this, just under half of staff who participated felt that there had been little or no impact on their practice. Most of these reported that the experience of the CARE Approach was positive due to the opportunity to review, reflect on and reconfirm existing practice, however some other participants were able to describe specific changes to their practice.
"It helped me re-evaluate what I needed to think about for the patient and it changed my approach with a good benefit for the patient and a good outcome for myself as well. It helped me take a wee step back and go in at it from a different angle". Participant, Site 1

"I hear it - they were all practising making a person feel comfortable when they come in, which is what we do anyway, but you can hear all the docs now being completely different in how they say "Oh hello - come in". You can hear it in the corridor...it has made a difference, definitely". Participant, Site 2

The changes were not confined to clinical staff. One participant who held a non-clinical role was able to identify how her communication skills were important in improving patient experience. This view was echoed by other facilitators and participants.

"Not that we are going to be seeing patients, but you know it just makes you more alert... to stop what you are doing for a minute and make sure you have got eye contact and full attention. Sometimes you have to go a bit further than that, be a wee bit more caring, maybe sit down with them for a minute if they are awfully upset. So yes, it's helped with that".

Participant, Site 5

Improved use of body language and non-verbal communication was reported by several participants. One practice nurse reported that as a result of the CARE sessions, she had been working to improve eye contact and concentration on the patient through minimising computer use and making short notes on paper. Other participants too reported increased awareness of language, barriers to communication with patients, and ability to recognise when a consultation was not going well and take steps to remedy that. The potential of this more holistic person-centred approach to consultations was recognised by many.

Table 3 Self-rated CARE Measure scores, $n=46$

\begin{tabular}{|c|c|c|c|c|}
\hline $\begin{array}{l}\text { CARE Measure item (Please rate how you feel } \\
\text { patients perceive you to be at...) }\end{array}$ & Average pre & Average post & Percentage difference & $p$-value \\
\hline 1. Making them feel at ease... & 3.87 & 3.93 & 1.69 & ns \\
\hline 2. Letting them tell their "story"... & 3.37 & 3.93 & 16.77 & .000 \\
\hline 3. Really listening to them... & 3.47 & 4.09 & 17.95 & .000 \\
\hline 4. Being interested in them as a whole person... & 3.70 & 4.17 & 12.94 & .001 \\
\hline 5. Fully understanding their concerns... & 3.35 & 3.89 & 16.23 & .001 \\
\hline 6. Showing care and compassion... & 3.71 & 4.15 & 11.88 & .002 \\
\hline 7. Being positive... & 3.62 & 4.04 & 11.63 & .000 \\
\hline 8. Explaining things clearly... & 3.43 & 3.98 & 15.82 & .000 \\
\hline 9. Helping them to take control... & 3.35 & 3.70 & 10.39 & .050 \\
\hline 10. Making a plan of action with them... & 3.33 & 3.89 & 16.67 & .000 \\
\hline
\end{tabular}


"We shouldn't underestimate the power of the doctor as a drug, that is what I feel I see now". Facilitator

\section{Discussion}

In the current study we have reported healthcare professionals' views of the CARE Approach learning tool following its use in a peer-facilitated pilot in five primary and community care settings in Scotland. Overall the results indicate that the CARE Approach was perceived as useful and relevant to practice across different disciplines and settings. The flexibility of the CARE Approach materials facilitated its delivery and implementation across the sites. The current study did not measure changes in patientreported views on practitioners' empathy, however participants' self-ratings of empathy improved between baseline and follow-up.

\section{Comparison with existing literature}

A recent Cochrane review has shown that interventions aimed at training healthcare providers to be more patientcentred in clinical consultations can be effective in teaching providers new skills [25]. Other studies have also shown that training practitioners in empathic approaches can lead to higher levels of perceived empathy by patients $[6,20,23,24]$. Thus the benefits reported by the participants in the present study are feasible in the light of current knowledge.

The current study used peer-facilitated training in conjunction with the CARE Approach manual [27] and the exact duration of this varied somewhat between the different sites. Group sessions were held on 4-6 occasions in each site, and lasted 1-2 hours. The optimal length of training in such approaches is not clear from the literature, with short-term training (of less than 10 hours) being possibly as effective as longer term training [25]. Most studies have focused on medical staff and to a lesser extent nurses and have overlooked other staff groups.

\section{Strengths and weaknesses of the current study}

The multi-disciplinary nature of the staff teams involved in these CARE Approach pilots was a strength of the current study. The mixed-methods design also maximised the opportunities (within the limits of the funding and time available) to gain both qualitative and quantitative data on a reasonably large number of participants, located in a diverse range of clinical, geographical and socio-economic locations in Scotland.

The study had several weaknesses. Firstly it was a before and after design and thus did not have a control group to compare changes with. Secondly, there was a considerable reduction in the rate of completion of the questionnaire before and after the intervention. The views of non-responders may have differed from those reported here. Thirdly the study did not assess the long term impact of the CARE Approach on the participants. Finally the effect of the intervention on patient experiences and outcomes was not measured.

Ideally, the CARE Measure would have been used on patients before, and after a period of time following, the healthcare practitioners' completion of the CARE Approach and at the same intervals in a control group. Improvements in participants' self-rated empathy scores may be a research participation or social desirability effect rather than attributable to the intervention, however the qualitative data is suggestive of noticeable improvements in practice worthy of further investigation.

\section{Implications for policy and practice}

The findings of this pilot study support the utility of the CARE Approach as a generic learning tool that multidisciplinary teams can use with the aim of maintaining and developing empathy and patient-centredness in clinical encounters. In future, the combined use of the CARE Approach with the CARE Measure would enable more robust evaluation of the impact of the approach. Together, the CARE Approach and CARE Measure may offer a feasible way to monitor and/or improve the effectiveness of national policy directives aimed at driving up the quality of the human aspects of healthcare [2]. For practices, the CARE Approach offers a convenient route to peer-supported learning at the local level, which could feed into practice audit cycles, appraisal and revalidation. Following this study, new guidance on using the CARE Approach to enhance interpersonal relationships within and between teams, and an additional module on to provide more in-depth guidance on 'Facilitating the CARE Approach' has been developed and incorporated into the current manual [27].

\section{Conclusions}

The current pilot study of the CARE Approach suggests it is useful to practitioners in primary and community care and can feasibly be used in peer facilitated learning groups. Further work is required to determine the utility of the approach when used in other ways (e.g. individual use rather than groups) and in other settings (such as secondary care) and to ascertain the effectiveness of the approach in maintaining or improving empathic, patientcentred communication in the longer-term.

\section{Competing interests}

$\mathrm{NF}$ and SH declare no competing interest. SM and $\mathrm{AB}$ are authors of a book about the CARE Approach and CARE Measure for which they will receive sales royalties.

\section{Authors' contribution}

NF and SH designed the study methods. SH conducted the data collection, interviews and analysis and drafted the initial report on which this paper is based. NF contributed to the data analysis and initial report. AB prepared an initial draft of this paper which was revised by NF, SH and SM. NF revised the manuscript following peer review. All authors read and approved the final manuscript. 


\section{Acknowledgements}

NHS Education for Scotland funded the implementation and evaluation of the pilot projects and Maggie Grundy and Audrey Taylor managed the work on behalf of the funder at all stages. The Scottish Government Long-Term Conditions Unit funded the initial development of the CARE Approach. Julie Dowds, Julie Hale and Joanne Winterbottom contributed to the evaluation design and conduct. The authors are grateful to all staff involved for their engagement with the pilots and the evaluation process.

\section{Author details}

${ }^{1}$ Lecturer in Alcohol Studies, Institute for Social Marketing, UK Centre for Tobacco and Alcohol Studies, University of Stirling, Stirling FK9 4LA, UK. ${ }^{2}$ Glasgow City Community Health Partnership: North-East Sector, Eastbank Health Promotion \& Training Centre, Academy Street, Glasgow G32 9AA, UK. ${ }^{3}$ Institute of Health and Wellbeing, University of Glasgow, 1 Horselethill Road, Glasgow G12 9LX, UK. " Primary Care Research, Institute of Health and Wellbeing, University of Glasgow, 1 Horselethill Road, Glasgow G12 9LX, UK.

Received: 4 April 2014 Accepted: 9 September 2014

Published online: 27 October 2014

\section{References}

1. World Health Organisation: Primary care: Putting people first in The world health report 2008: Primary Health Care, Now more than ever. Geneva: WHO; 2008.

2. The Scottish Government: The Healthcare Quality Strategy for NHSScotland. Edinburgh: The Scottish Government; 2010.

3. Department of health [England]: Equity and Excellence: Liberating the NHS London: Department of Health; 2010.

4. Welsh Government: Working Differently - Working Together, A Workforce and Organisational Development Framework. Cardiff: Welsh Government; 2012

5. Campbell SM, Roland MO, Buetow S: Defining quality of care. Soc Sci Med 2000, 51:1611-1625.

6. Mercer SW, Reynolds W: Empathy and quality of care. BJGP 2002 52(Supplement):S9-S12.

7. Mercer SW, Howie JGR: CQI-2, a new measure of holistic, interpersonal care in primary care consultations. BJGP 2006, 56(525):262-268.

8. Mercer SW, Watt GCM, Maxwell M, Heaney DH: The development and preliminary validation of the Consultation and Relational Empathy (CARE) Measure: an empathy-based consultation process measure. Fam Pract 2004, 21(6):699-705.

9. Mercer SW, McConnachie A, Maxwell M, Heaney DH, Watt GCM: Relevance and performance of the Consultation and Relational Empathy (CARE) Measure in general practice. Fam Pract 2005, 22(3):328-334.

10. Aomatsu M, Abe H, Yasui H, Suzuki T, Sato J, Ban N, Mercer SW: Validity and reliability of the Japanese version of the CARE Measure in a general medicine outpatient setting. Fam Pract 2013, [e-pub ahead of print].

11. Mercer SW, Fung CSF, Chan FWK, Wong FYY, Wong SYS, Murphy D: The Chinese-version of the CARE Measure reliably differentiates between doctors in primary care. BMC Fam Pract 2011, 12:43

12. Neumann $M$, Wirtz $M$, Bollschweiler $E$, Warm M, Wolf J, Pfaff $H$ : Psychometrische Evaluation der deutschen Version des Messinstruments "Consultation and Relational Empathy" (CARE) am Beispiel von Krebspatienten. / Psychometric evaluation of the German version of the "Consultation and Relational Empathy" (CARE) measure at the example of cancer patients. Psychother Psychosom Med Psychol 2008, 58:5-15.

13. Little P, Everitt H, Williamson I, Moore M, Warner G, Gould C, Ferrier K, Payne S: Observational study of effect of patient-centredness and positive approach in primary care on outcomes of primary care consultations. BMJ 2001, 323:908-911.

14. Griffin S, Kinmonth A, Veltman M, Gillard S, Grant J, Stewart M: Effect on health-related outcomes of interventions to alter the interaction between patients and practitioners: a systematic review of trials. Ann Fam Med 2004, 2:595-608. Ann Fam Med 2004: 2:595-608.

15. Bikker AP, Mercer SW, Reilly D: A pilot prospective study on the consultation and relational empathy, patient enablement, and health changes over 12 months, in patients going to the Glasgow Homoeopathic Hospital. J Alt Comp Med 2005, 11(4):591-600.

16. Mercer SW, Neumann M, Wirtz W, Fitzpatrick B, Vojt G: Effect of General Practitioner empathy on patient enablement, and patient-reported outcomes in primary care in an area of high socio-economic deprivation in Scotland - a pilot prospective study using structural equation modelling. Patient Educ Couns 2008, 73:240-245.

17. Derksen F, Bensing J, Lagro-Janssen A: Effectiveness of empathy in general practice: a systematic review. BJGP 2013, 63(606):76-84.

18. Rakel D, Barrett B, Zhang Z, Hoeft T, Chewning B, Marchand L, Scheder J: Perception of empathy in the therapeutic encounter: effects on the common cold. Patient Educ Couns 2011, 85(3):390-397.

19. Hojat M, Louis DZ, Markham FW, Wender R, Rabinowitz C, Gonnella JS: Physicians' empathy and clinical outcomes for diabetic patients. Acad Med 2011, 86(3):359-364.

20. Neumann M, Bensing J, Mercer S, Ernstmann N, Ommen O, Pfaff H: Analyzing the "nature" and "specific effectiveness" of clinical empathy: a theoretical overview and contribution towards a theory-based research agenda. Patient Educ Couns 2009, 74:339-346.

21. Mercer SW, Jani B, Wong SY, Watt GCM: Patient enablement requires physician empathy: a cross-sectional study of general.practice consultations in areas of high and low socioeconomic deprivation in Scotland. BMC Fam Pract 2012, 13:6.

22. Neumann M, Edelhauser F, Tauschel D, Fischer MR, Wirtz M, Woopen C, Haramati A, Scheffer C: Empathy decline and its reasons: a systematic review of studies with medical students and residents. Acad Med 2011, 86(8):996-1009.

23. Riess H, Kelley JM, Bailey RW, Dunn EJ, Phillips M: Empathy training for resident physicians: a randomized controlled trial of a neuroscienceinformed curriculum. J Gen Intern Med 2012, 27(10):1280-1286.

24. Batt-Rawden SA, Chisholm MS, Anton B, Flickinger TE: Teaching empathy to medical students: an updated systematic review. Acad Med 2013, 88(8):1171-1177.

25. Dwamena F, Holmes-Rovner M, Gaulden C, Jorgenson S, Sadigh G, Sikorski A, Lewin S, Smith RC, Coffey J, Olomu A: Interventions for providers to promote a patient-centred approach in clinical consultations. Cochrane Database Syst Rev 2012, Issue 12. Art. No.: CD003267. doi:10.1002/14651858.CD003267.pub2.

26. Bikker AP, Mercer SW, Cotton P: Connecting, Assessing, Responding and Empowering (CARE): a universal approach to person-centred, empathic healthcare encounters. Educ Prim Care 2012, 23(6):454-457.

27. Bikker AP, Cotton P, Mercer SW: Embracing Empathy in Healthcare. A Universal Approach To Person-Centred, Empathic Healthcare Encounters. London, New York: Radcliffe; 2014. ISBN-13: 9781909368187.

28. Health Research Authority: Is My Project Research? Decision Tool; [http:// www.hra-decisiontools.org.uk/research/ Accessed 28th August, 2014]

29. Thomas DR: A general inductive approach for analyzing qualitative evaluation data. Am J Eval 2006, 27(2):237-246.

\section{doi:10.1186/s40639-014-0006-8}

Cite this article as: Fitzgerald et al:: Enhancing empathy in healthcare: mixed-method evaluation of a pilot project implementing the CARE Approach in primary and community care settings in Scotland. Journal of Compassionate Health Care 2014 1:6.

\section{Submit your next manuscript to BioMed Central and take full advantage of:}

- Convenient online submission

- Thorough peer review

- No space constraints or color figure charges

- Immediate publication on acceptance

- Inclusion in PubMed, CAS, Scopus and Google Scholar

- Research which is freely available for redistribution 